\title{
A Study on Variants of Haemoglobin in Barak Valley, Assam
}

\author{
Dr. Lalpeklawm Hmar ${ }^{1}$, Dr. Naba Ratna Nath ${ }^{1}$, Dr. Shrabani Barman ${ }^{2}$ \\ ${ }^{I}$ Demonstrator, Department of Physiology, Silchar Medical College and Hospital \\ ${ }^{2}$ Professor and Head, Department of Physiology, Silchar Medical College and Hospital
}

\begin{abstract}
Haemoglobin variants are inherited disorders of haemoglobin, it is one of the commonest single gene disorder affecting millions of people all over the world, including India. Haemoglobinopathies cause major genetic and public health problems. So, the present study is carried out to find carriers among the healthy individuals to prevent silent transmission of the disorder among the population.

Materials and Method: In this study a total of 200 subjects were included amongst the medical students, nurses and nursing students of Silchar Medical College and Hospital for analysis of haemoglobin variants. The study was performed by Horizontal electrophoresis Pherotank by using cellulose acetate membrane and Tris buffer at pH 8.5 .

Results: Out of 200 subjects studied, 49 subjects had abnormal haemoglobin type. Hb E trait was the most predominant with 31(15.5\%) incidence, followed by $9(4.50 \%)$ of HbE/thalassemia, and $6(3 \%)$ subjects were also found to have $\mathrm{HbE}$ disease. It was also seen that thalassemia trait was found in 3 (1.50\%) subjects. It was also found that out of total haemoglobin variants 24(48.97\%) subjects of $\mathrm{HbE}$ trait were anaemic and 7(14.20\%) were non-anaemic . 5(10.20\%) subjects of HbE disease were anaemic and 1 subject was found to be non- anaemic.
\end{abstract}

Keywords: Barak Valley Assam, Electrophoresis, Haemoglobinopathies.

\section{Introduction}

Haemoglobin variant is an inherited autosomal recessive disorder of haemoglobin. The structure of haemoglobin variants is similar to normal haemoglobin $(\mathrm{HbA})$ except there is alteration in the sequence of amino acids usually in the $\beta$-chain. Haemoglobinopathies can be divided into two groups - the structural haemoglobin variants due to single point mutation in the globin structure (like ${ }^{\mathrm{HbS}}, \mathrm{C}, \mathrm{D}$, and E) and the thalassemia, where the rate of synthesis of globin chain is inefficient ${ }^{[1]}$. The clinical spectrums of the disorders vary from asymptomatic conditions to serious disorders like death in utero. They may present as haemolytic anaemia, erythrocytosis as seen in haemoglobin variant $\mathrm{Hb}$ Yakima $\left(\beta^{99 \mathrm{Asp} \rightarrow \mathrm{His}}\right)^{[2]}$, cyanosis, jaundice or vasoocclusive phenomenon.

Haemoglobinopathies are the common single-gene disorders, with worldwide prevalence, including India. World Health Organization (WHO) estimated that about $5 \%$ of world populations are the carriers ${ }^{[3]}$. In India the gene frequency of haemoglobinopathies is $4.2 \% .{ }^{[4]}$. The frequency of $\mathrm{Hb} \mathrm{E}$ in Assam is $52 \%{ }^{[5]}$.

The studies of haemoglobin disorders are important. As it is an inherited disorder, many haemoglobin variants are completely clinically asymptomatic and haematologically silent ${ }^{[6]}$. Accurate and timely detection of various haemoglobin variants can prevent occurrence of more serious haemoglobinopathies.

The study community comprises of students, nurses and nursing student of various ethnic groups from Silchar Medical College and Hospital, Ghungoor, which is located in Silchar, Cachar district in Southern part of Assam generally known as Barak Valley. The present study was undertaken to evaluate the prevalence of haemoglobin variants in Barak Valley.

\section{Materials and Methods}

The study was conducted in the Department of Physiology in collaboration with Department of Pathology, Silchar Medical College. This is a hospital based, cross-sectional type of study. The study population comprised of medical students, nursing students and nurses of Silchar Medical College. A total of 200 subjects both male and female in the age groups of 18 to 25 years were included in the study. The subjects with history of recent blood transfusion were excluded from the study. The study was approved by the Institutional Ethical Committee.

After explaining the procedure of the study to the subjects, written informed consent was obtained. About $4-5 \mathrm{ml}$ of venous blood was collected under proper asceptic condition from the anticubital vein in EDTA vial. About $2 \mathrm{ml}$ of blood was used for complete haemogram analysis. Another $2 \mathrm{ml}$ was taken for preparation of haemolysates. The complete haemogram analysis was done in a Sysmex 5 part haematology analyzer. The principle of the analyzer is based on impedance and optical methods. The parameters taken for this study were$\mathrm{Hb} \%, \mathrm{RBC}, \mathrm{Hct}, \mathrm{MCV}, \mathrm{MCH}, \mathrm{MCHC}$ and RDW-CV. The subjects were classified into two groups: anaemic 
and non-anaemic groups. According to WHO criteria, male subjects with $\mathrm{Hb}<13 \mathrm{gm} / \mathrm{dl}$ and $\mathrm{MCHC}<34 \%$, females, non-pregnant with $\mathrm{Hb}<12 \mathrm{gm} / \mathrm{dl}$ and $\mathrm{MCHC}<34 \%$ and female, pregnant with $\mathrm{Hb}<11 \mathrm{gm} / \mathrm{dl}$ and $\mathrm{MCHC}<34 \%$ were considered anaemic ${ }^{[7]}$.

With the haemolysates electrophoresis was performed by Horizontal electrophoresis Pherotank by using cellulose acetate membrane dipped in Tris buffer at $\mathrm{pH}$ 8.5. The principle of electrophoresis was, at alkaline $\mathrm{pH}$, haemoglobin is being a negatively charged protein will migrate toward the anode. Structural variants that have a change in the charge on the surface of the molecule at alkaline $\mathrm{pH}$ will separate from $\mathrm{HbA}$. Haemoglobin variants that have an amino acid substitution that is internally sited may not separate and those that have an amino acid substitution that has no effect on overall charge will not separate by electrophoresis.

The prepared slides by cellulose acetate membrane were then analyzed by Scanion densitometer.

Statistical analysis was done by using Microsoft Office Excel and SPSS version 12. p- Value less than 0.05 is considered as significant.

\section{Results}

A total of 200 subjects were screened for haemoglobin variants. 83(41.50\%) subjects were found to be anaemic and 117(58.50\%) subjects non-anaemic [Table-1]. Out of 200 subjects, 151 (75.50\%) had normal adult haemoglobin $(\mathrm{HbA})$ type and 49 subjects have abnormal haemoglobin type. Of the subjects with normal haemoglobin type( $\mathrm{HbA}) 43(21.50 \%)$ were anaemic and $108(54 \%)$ were non-anaemic. Whereas, $40(20.00 \%)$ of haemoglobin variants were anaemic and $9(4.5 \%)$ were non-anaemic (Table-2).

Amongst the abnormal haemoglobin variants, $\mathrm{Hb} \mathrm{E}$ trait was most predominant with 31(15.5\%) incidence, followed by $9(4.50 \%)$ subjects with $\mathrm{HbE} /$ thalassemia and $6(3 \%)$ subjects were found to have $\mathrm{HbE}$ disease. Thalassemia trait was found in $3(1.50 \%)$ subjects [Fig.1]. Out of total haemoglobin variants 24(48.97\%) of $\mathrm{HbE}$ trait were anaemic, 7(14.20\%) were non-anaemic . 5(10.20\%) of $\mathrm{HbE}$ disease were anaemic and 1 was non- anaemic. Among the subjects with $\mathrm{HbE} /$ thalassemia, all the subjects $9(18.30 \%)$ were anaemic [Table -3]. Various haematological parameters with mean values \pm SD associated with different haemoglobin variants were shown in [Table-4]. The mean RBC count was found to be normal, mean Hb, Hct, $\mathrm{MCV}, \mathrm{MCH}$, and MCHC were decrease and mean RDW-CV was found to increased in all of them. Significant difference was not found on comparison of various haematological parameters of the group comprising HBE trait and that of HbE disease (Table- 5).

Table-1: Distribution of subjects into Anaemic or Non-Anaemic groups

\begin{tabular}{|l|l|l|}
\hline Anaemic & Non-Anaemic & Total \\
\hline $83(41.50 \%)$ & $117(58.50 \%)$ & 200 \\
\hline
\end{tabular}

Table-2: Distribution of Haemoglobin types on the basis of Hb level

\begin{tabular}{|l|l|l|}
\hline Hb types on electrophoresis & Anaemic & Non-Anaemic \\
\hline Normal $\mathrm{Hb}$ type $(\mathrm{HbA})$ & $43(21.50 \%)$ & $108(54.00 \%)$ \\
\hline Abnormal Hb type & $40(20.00 \%)$ & $9(4.50 \%)$ \\
\hline Total & 83 & $117(100)$ \\
\hline
\end{tabular}

Table-3: showing distribution of $\mathrm{HbE}$ variants in anaemics and non-anaemics

\begin{tabular}{|l|l|l|l|}
\hline Group & HbE trait & HbE Disease & HbE/Thalassemia \\
\hline Anaemic & $24(48.97 \%)$ & $5(10.20 \%)$ & $9(18.30 \%)$ \\
\hline Non-Anaemic & $7(14.20 \%)$ & $1(2 \%)$ & 0 \\
\hline
\end{tabular}

Table-4: Haematological parameters in various type of haemoglobin

\begin{tabular}{|l|l|l|l|l|l|l|l|l|}
\hline $\begin{array}{l}\text { Electrophoresis } \\
\text { diagnosis }\end{array}$ & $\begin{array}{l}\text { No. } \\
\text { Subjects }\end{array}$ & $\mathbf{H b} \mathbf{g m} / \mathbf{L}$ & $\begin{array}{l}\mathbf{R B C} \\
\mathbf{1 0} / \boldsymbol{\mu} \mathbf{L}\end{array}$ & $\mathbf{H c t}(\mathbf{\%})$ & $\mathbf{M C V}(\mathbf{f l})$ & $\mathbf{M C H}(\mathbf{p g})$ & $\begin{array}{l}\mathbf{M C H C} \\
\mathbf{( g / L )}\end{array}$ & $\begin{array}{l}\text { RDW } \\
\mathbf{C V}\end{array}$ \\
\hline HbE trait & 31 & $11.12 \pm 1.67$ & $4.93 \pm 0.62$ & $35.86 \pm 4.27$ & $74.32 \pm 8.57$ & $22.36 \pm 2.55$ & $30.65 \pm 3.49$ & $17.60 \pm 4.40$ \\
\hline HbE Disease & 6 & $11.41 \pm 1.33$ & $5.79 \pm 0.90$ & $35.23 \pm 3.41$ & $61.28 \pm 4.16$ & $19.78 \pm 1.23$ & $32.36 \pm 1.97$ & $18.36 \pm 1.73$ \\
\hline HbE Thalassemia & 9 & $7.95 \pm 2.00$ & $4.35 \pm .086$ & $26.46 \pm 4.72$ & $61.12 \pm 4.84$ & $18.08 \pm 1.49$ & $29.78 \pm 3.32$ & $29.39 \pm 11.76$ \\
\hline Thalassemia trait & 3 & $11.27 \pm 2.45$ & $5.38 \pm 1.34$ & $36.54 \pm 5.30$ & $69.17 \pm 9.50$ & $21.07 \pm 1.41$ & $30.64 \pm 2.56$ & $16.57 \pm 2.56$ \\
\hline
\end{tabular}

Data are mean \pm SD; Hb: Haemoglobin; RBC: Red Blood Corpurscles; Hct: Haematocrit;Mcv: Mean Corpuscular Volume; MCH: Mean Corpuscular Haemoglobin; MCHC: Mean Corpuscular Haemoglobin; RDW$\mathrm{CV} ;$ Red cell Diameter Width Coefficient of Variation

Table-5: Comparison of RBC indices in HbE disease and HbE Trait

\begin{tabular}{|l|l|l|l|}
\hline \multirow{2}{*}{ Haematological parameters } & \multicolumn{3}{|l|}{ HbE Disease and HbE Trait } \\
\cline { 2 - 4 } & $\mathrm{t}$-value & Degree of freedom & Level of Significance \\
\hline $\mathrm{RBC}$ & $\mathrm{T}=0.685$ & $\mathrm{df}=5$ & $\mathrm{P}>0.05$ \\
\hline $\mathrm{Hb}$ & $\mathrm{T}=(-) .286$ & $\mathrm{df}=5$ & $\mathrm{P}>0.05$ \\
\hline
\end{tabular}




\begin{tabular}{|l|l|l|l|}
\hline Hct & $\mathrm{T}=(-) .988$ & $\mathrm{df}=5$ & $\mathrm{P}>0.05$ \\
\hline MCV & $\mathrm{T}=(-) 2.565$ & $\mathrm{df}=5$ & $\mathrm{P}=0.05$ \\
\hline MCH & $\mathrm{T}=(-) 1.482$ & $\mathrm{df}=5$ & $\mathrm{P}>0.05$ \\
\hline MCHC & $\mathrm{T}=1.916$ & $\mathrm{df}=5$ & $\mathrm{P}>0.05$ \\
\hline RDW & $\mathrm{T}=0.882$ & $\mathrm{df}=5$ & $\mathrm{P}>0.05$ \\
\hline
\end{tabular}

Fig.1 Showing Distribution of Different types of Haemoglobin

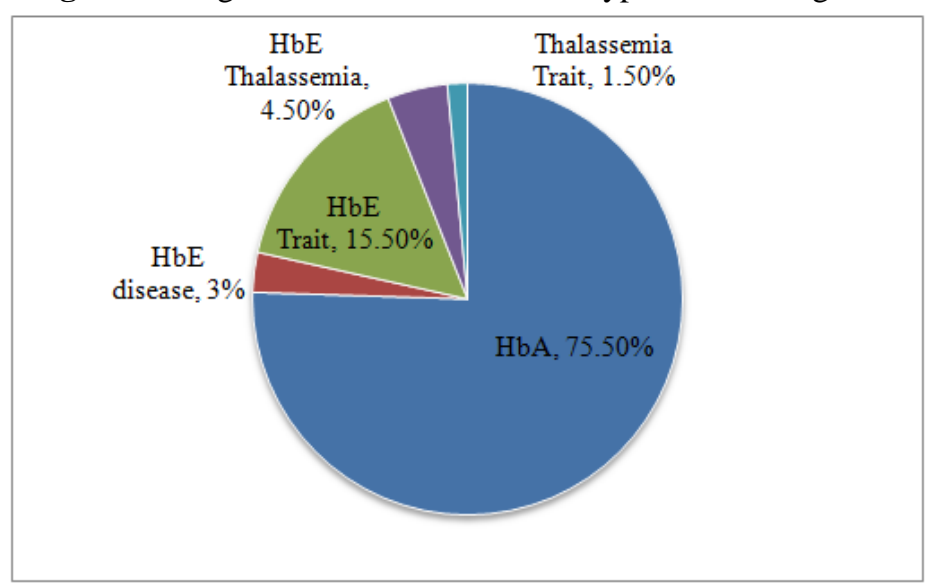

\section{Discussion}

Haemoglobinopathies are group of inherited blood disorders, primarily affecting the globin moiety of the haemoglobin molecule. It can be the structural haemoglobin variants due to single point mutation or thalassemias where the rate of synthesis of globin chain is ineffective. Haemoglobinopathy constitutes a very important group of diseases in tropical countries. The prevalence of carriers of haemoglobin gene variants is $5.2 \%$ of world population ${ }^{[3]}$.

There are many different types of haemoglobinopathies and among them some types are frequently encountered in this part of the world. Report on previous study showed that $\mathrm{HbE}$ is the most common haemoglobin variants in Asian population affecting 30 million inhabitant of Southeast Asian ${ }^{[8]}$. The most common monogenic disorder of the autochthonus inhabitants of Northeastern region of India are HbE with variable gene frequencies ${ }^{[9]}$. In Assam, the frequency of $\mathrm{HbE}$ is $52 \%{ }^{[5]}$. Bodo Kachari population of Assam have high incidence of $\mathrm{HbE}$ mutation with $64.5 \%$, the highest frequency ever found in the world ${ }^{[10]}$. There is also high incidence among the Ahoms, Tea Garden Labourers, Mishing, Deori and Sonowal. Similarly, in our study abnormal haemoglobin were detected in 49 subjects out of 200 subjects. The present study shows high incidence of $\mathrm{HbE}$ variants $(23.00 \%)$, of which $15.50 \%$ were $\mathrm{HbE}$ trait, $03.00 \%$ were $\mathrm{HbE}$ disease and $4.50 \%$ were $\mathrm{HbE} / \mathrm{Thalassemia.}$

National Family and Health Survey -3(NFHS-3) reported that in Assam high level of anaemia is prevalence for both women and men ${ }^{[11]}$. Conforming to the previous report in our study, out of 200 subjects, $83(41.5 \%)$ were anaemic.

Madhusnata De et al ${ }^{[12]}$ in 2006 found that anaemia due to haemoglobinopathies is more prevalent in Assam and Tripura. Similarly, in the present study 41(20.5\%) of haemoglobin variants were anaemic and only $9(4.5 \%)$ of haemoglobin variants were non-anaemic. So, most of the haemoglobin variants were anaemic.

In our study, out of total haemoglobin variants $24(48.97 \%)$ of $\mathrm{HbE}$ trait were anaemic, $7(14.28 \%)$ were non-anaemic. 5(10.2\%) of $\mathrm{HbE}$ disease were anaemic and 1 was non- anaemic. All the 9(18.36\%) subjects of $\mathrm{HbE} /$ Thalassemia were anaemic. Similarly, the various studies reported that anaemia was found among the $\mathrm{HbE}$ variants $[9,13]$

In this study the mean RBC count was normal. Most of the subjects with haemoglobin variants have microcytic hypochromic type of anaemia with decreased in the mean MCV and MCH. This finding is in agreement with other studies ${ }^{[13]}$. Usually RDW is normal in pure thalassemia trait and increased in pure nutritional type of anaemia ${ }^{[6]}$. In contrary to these findings, mean RDW was found to increase in all the subjects with Haemoglobin variants. The same findings were also reported by Baruah et al. ${ }^{13]}$ and Mukhopadhyay et $\mathrm{al}^{[14]}$. Increase in RDW is not a usual finding of pure haemoglobinopathies. Probably there is associated nutritional deficiency among the subjects, which is a common finding in the population of this region.

Comparing the haematological parameters of the group comprising $\mathrm{HbE}$ trait and that of $\mathrm{HbE}$ disease, it was found that there was no significant difference in the RBC count, Hb, Hct, MCV, MCH, MCHC and RDW of the two groups. 
This study showed that anaemia was present despite of absence of haemoglobinopathies in some subjects. However, the anaemic subjects with both $\mathrm{HbA}$ type and haemoglobinopathies were not screened for any other factors like nutritional deficiencies that might have caused anaemia in them. It was out of the scope of the present study. Hb typing and the study of red cell indices, provide valuable information in the diagnosis of different haemoglobinopathies. The RBC indices specially MCV and MCH are found to be low in different haemoglobinopathies and are used as a screening tool in haemoglobinopathies ${ }^{[6]}$.

\section{Conclusion}

High incidence of haemoglobinopathies is reported in the Northeastern region of India. It is a common cause of anaemia. In this study, the prevalence of haemoglobinopathy was evaluated among the medical students, nursing students and nurses of Silchar Medical College, Silchar Assam. Haemoglobin E is found to be the most common haemoglobinopathy. Haemoglobinopathy is an inherited disorder, and its definitive treatment is not affordable to all the classes of population. It often becomes a huge burden on the patient, their relatives and the society. It can be prevented by creating awareness, population screening, prenatal diagnosis, premarital counseling and genetic counseling. This study was done to detect healthy carriers even among the non- anaemic individuals to prevent more serious damage to the future generation.

\section{Acknowledgement}

The authors are thankful to Dr. Debasish Datta, Professor, Department of Pathology, SMCH, Gungoor for his help and the blood donors for sample study for their kind co-operation in this study.

\section{References}

[1]. Chahal, S.M.S and Rupinder Bansal, Haemoglobin Variants in North Indian Populations, Proteomic Laboratory, Department of Human Biology, Punjabi University, Anthropologist, 2005, Vol.7(1): 1-6

[2]. Longo, Fauci, Kasper, Hauser, Jamsison \& Loscalzo , Harrison's Principles of Internal Medicine, McGraw-Hill companies Inc, USA, 2012, $18^{\text {th }}$ Edition, P-852-859

[3]. Modell B \& Darlison M , Global epidemiology of hemoglobin disorders and derived service indicators, Bull World Health Organ, 2008,Vol. 86: 480-87

[4]. Patne Shashikant, C.U \& Jyoti Shukla, Hemoglobin E disorders in Eastern Uttar Pradesh, Indian Journal of Pathology and Microbiology, 2009, Vol.52 (1), January-March

[5]. Patel, J. et al, Prevalence of Haemoglobinopathies in Gujarat, India: A Cross-Sectional Study, The Internet Journal of Hematology, 2009, Vol.5 No.1

[6]. Dacie and Lewis, Practical Haematolgy, Elsevier Publications, 10th Edition, P-14-15, 45,272-296

[7]. Park K, Park's Text Book of Prevention and Social Medicine, 2013, 22nd Edition, Bhanot Publication, Jabalpur, India

[8]. Sharma, S.K. \& J. Mahanta, Prevalence of Haemoglobin Variants in Malaria Endemic in Northeast India, Journal of Biological Sciences, 2009, Vol.9: 288-291

[9]. Sharma, Santanu K \& Jagadish Mahant, Prevalence of Haemoglobin E among Assamese Sikh community, Current Science,2013, Vol.104, No.8, 25 April

[10]. Das Swapan Kumar et al.High Incidence of Haemoglobin-E in Tribal Populations of Tripura, North East India., Anthropologist Special Issue,2002, No. 1;105-108

[11]. National Family Health Survey-3, (NFHS-3), www.hetv.org/india/nfhs/nfhs.3/NFHS-3chapter-10-nutrition-and-Anaemia.pdf, 200506, Vol.(1)P-309-312

[12]. Madhusnata De. et al, Anemia and hemoglobinopathies in tribal population of Eastern and North-eastern India, Hematology, October/December, 2006, Vol.11(5/6): 371-373

[13]. Baruah et al, Pattern of hemoglobinopathies and thalassemia in upper Assam region of North Eastern India: High liquid chromatography studies in 9000 patients. Indian J. Path and Microbio, 2014, Vol.57 (2), April-June

[14]. Mukhopadhyay et al, Spectrum of Haemoglobinopathies in West Bengal, India: A CE-HPLC Study on10407 Subjects. Indian J. Hematol Transfus, 2015, Vol.31 (1): 98-103, Jan-March. 